Saudi Journal of Medical and Pharmaceutical Sciences

Abbreviated Key Title: Saudi J Med Pharm Sci

ISSN 2413-4929 (Print) |ISSN 2413-4910 (Online)

Scholars Middle East Publishers, Dubai, United Arab Emirates

Journal homepage: https://saudijournals.com

Case Report

\title{
Thyroid Diffuse Large B cell Lymphoma: A Case Report
}

Ait Taleb Oum'hand Hajar", Belhaj Najoua, Mahiou Noureddine, Benyahia Zainab, Nitassi Sophia, Oujilal Abdelilah and Essakalli Leila

ENT Department, Hospital of Speciality of Rabat, University Hospital Avicenne, Rabat, Morocco

\begin{tabular}{ll}
\hline DOI: $10.36348 /$ sjmps.2020.v07i04.005 & | Received: 02.11.2020 | Accepted: 10.11.2020 | Published: 29.04.2021 \\
*Corresponding author: Ait Taleb Oum'hand Hajar &
\end{tabular}

\section{Abstract}

Thyroid diffuse large B cell lymphoma (DLBCL) presents typically as a rapidly growing neck mass that is sometimes accompanied by respiratory compression symptoms. It is more predominant in women and has a peak onset age of 50 to 70 years [1]. DLBCL should be treated with chemotherapy and radiotherapy after diagnosis through biopsy, and extensive surgery should be avoided. Here we describe a rare case of 63-year-old woman who was admitted in our ENT department due to rapidly growing (2 months), painful thyroid enlargement with compressive cervical symptoms.

Keywords: Thyroid Diffuse Cell Lymphoma.

Copyright (C) 2021 The Author(s): This is an open-access article distributed under the terms of the Creative Commons Attribution 4.0 International License (CC BY-NC 4.0) which permits unrestricted use, distribution, and reproduction in any medium for non-commercial use provided the original author and source are credited.

\section{INTRODUCTION}

Primary thyroid lymphoma (PTL) is a rare entity and is defined as a lymphoma involving only the thyroid gland or the thyroid gland and regional lymph nodes. There are two different histological types' diffuse large B cell lymphoma (DLBCL) and mucosaassociated lymphoid tissue (MALT) lymphoma. The diagnosis is mainly based on biopsy and it can be a challenge since it is a rare pathology and may influence the treatment $[1,2]$.

We report the case of a 63 years old woman consulting in our ENT department, Hospital of speciality of Rabat Morocco for primary and isolated thyroid diffuse large B cell lymphoma (DLBCL).

\section{Case Report}

We report the case of a 63-year-old woman who was admitted in our ENT department due to rapidly growing (2 months), painful thyroid enlargement with compressive cervical symptoms (dysphonia quickly followed by dyspnea then dysphagia). There was no known history of cervical irradiation or family history of thyroid cancer.

Upon physical examination, there were diffuse ulcerative skin lesions with multiple areas of necrosis covering almost the entire cervical region and extending to the thorax (figure 1). The general physical examination didn't find any hepatomegaly, or splenomegaly or other clinically palpable lymphnods in the body. Bloodcount cells didn't show any disorder.

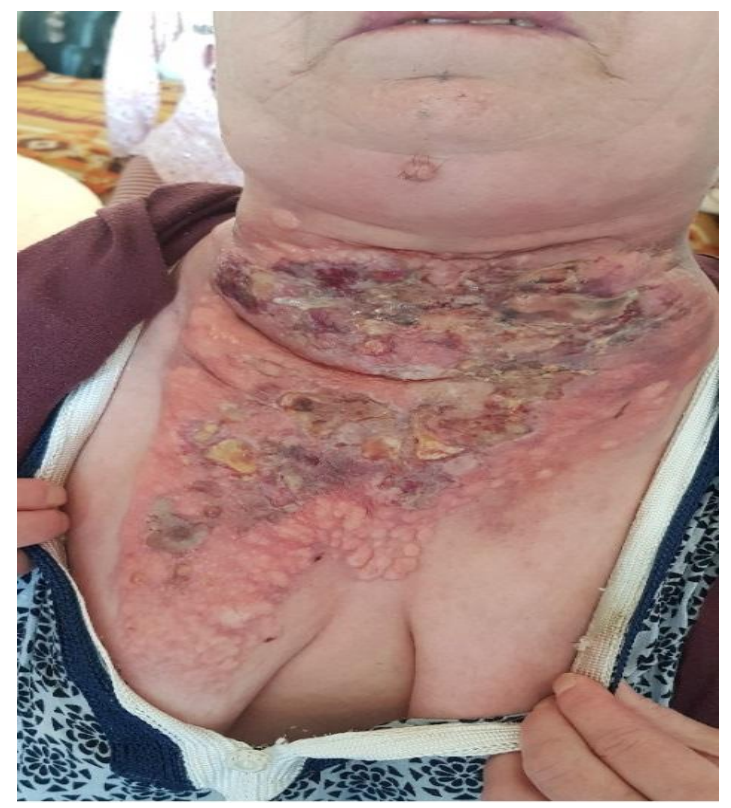

Fig-1 : Front view of the patient showing a diffuse anterior cervical process with multiple areas of necrosis extending to the thorax

Cervical and thoracic CT scans were done showing an anterior cervical infiltrating tissue mass, heterogeneously enhanced by the contrast product and delimiting hypodense areas of necrosis. This mass infiltrates the thyroid gland almost completely and extends to the glottic and subglottic floors with a 
reduction in the glottic lumen. This tissue process also infiltrates the upper esophagus with the presence of multiple bilateral cervical lymphadenopathies.

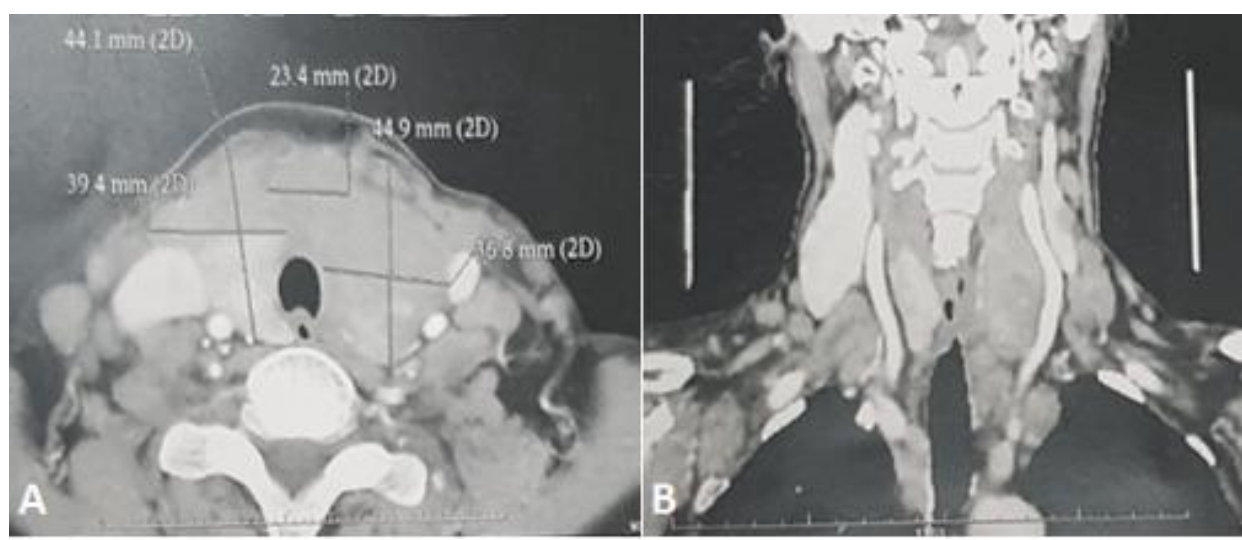

Fig-2: Contrast enhanced axial (A) and coronal (B) soft tissue window CT showing a significant enlargement of the thyroid tumor and lymph nodes causing airway compression.

Owing to the requirement for obtaining a histopathological diagnosis, incisional biopsy was performed under local anesthesia. Histopathological examination showed undifferentiated and infiltrating malignant tumor proliferation. Immunohistochemical study was done. The immunohistochemistry showed lymphoid tumor cells expressing CD45, these cells are of phenotype B expressing the CD20, and they diffusely express MUM1. The anti-cytokeratin antibody (AE1) is negative and Ki-67 Proliferation Index was estimated at $90 \%$, On the basis of these findings, a final diagnosis of thyroid localization of diffuse large cell B lymphoma of the non-germinal center type was established.

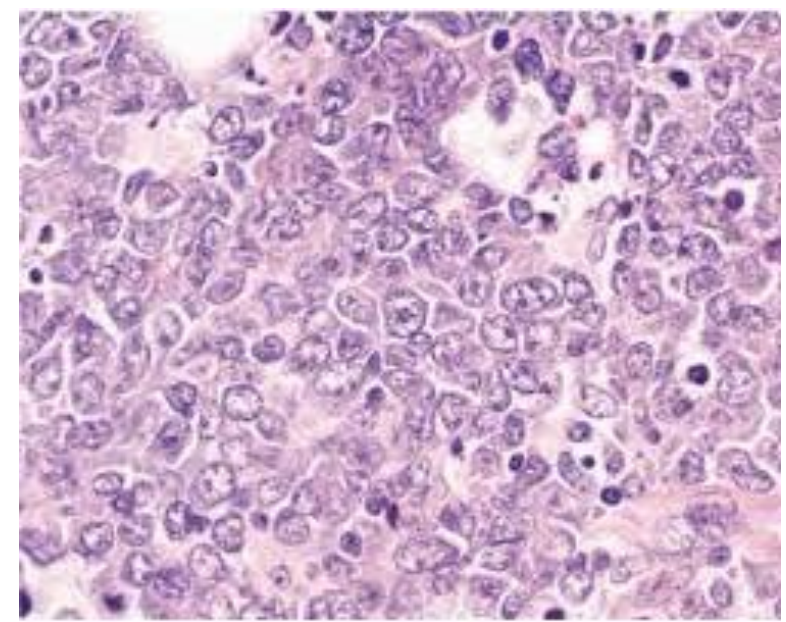

Fig-3 : View of the biopsy specimen showing round-to-oval cells with high nuclear/cytoplasmic ratio, coarse chromatin and numerous mitoses $(\mathrm{H} \& \mathrm{E}, 400)$.

A multidisciplinary consultation meeting was carried out directly after the confirmation of the diagnosis. It was decided to treat the patient according to a regimen of 4 drugs known as CHOP (cyclophosphamide, doxorubicin, vincristine, and prednisone), plus the monoclonal antibody that recognizes the CD20 protein: Rituximab in cycles 3 weeks apart.At the end of the first chemotherapy session the patient had presented with laryngeal dyspnea, which required an emergency tracheotomy. The realization of the tracheostomy was complicated by a bilateral pneumothorax. Despite the immediate drainage of the pneumothorax, the patient died of respiratory complications.

\section{DISCUSSION}

Primary thyroid lymphoma(PTL) is rare, accounting for only $5 \%$ of thyroid malignancies and $2 \%$ of extranodal lymphomas.[2-3] B-cell type nonHodgkin lymphoma(NHL) is a frequently described type of PTL, while Hodgkin's and T-cell lymphoma are rare [3] The secondary thyroid lymphoma originates from a disseminated non-thyroidal neoplasia that metastasizes to the thyroid gland. It is clinically important to discriminate between primary or secondary lymphoma of the thyroid as the treatment and prognosis differ significantly. The secondary lymphoma of the thyroid invariably is a widespread disease and the mortality rate is higher, as opposed to primary thyroid lymphoma in early stages [4].

Thyroid lymphoma typically presents as a rapidly growing neck mass associated or not with lymphadenopathy which is sometimes accompanied by respiratory compression symptoms. It is more predominant in women and has a peak onset age of 50 to 70 years [5-6].

The risk of thyroid lymphoma is high in individuals with a history of chronic thyroiditis, such as Hashimoto's thyroiditis [7-8]. According to some publications, Hashimoto's disease is associated with more than $90 \%$ of the PTL [9]. This close relationship is probably due to chronic antigenic stimulation leading to malignant transformation [10]. 
FNA (fine needle aspiration) is being used more frequently for the diagnosis of tumors, especially in the thyroid. However, results on its effectiveness are conflicting, with a reported sensitivity ranging from $55 \%$ to $86 \%[11,12]$. A study made by Matsuzaka et al reported that 65 out of 83 patients $(78.3 \%)$ had been correctly diagnosed.13 The authors recommend incisional biopsy (IB) in all cases to establish the final diagnosis. In our case, incisional biopsy was performed straight away.Diagnosis is based on the presence of a combination of morphologic features and immunophenotyping, determined by flow cytometry and immunohistochemistry which involves the presence of tumor cells of a lymphoid nature expressing CD45, CD20 and a coefficient of cell proliferation Ki67 most often greater than $40 \%$ and can reach 90\%[13].

The therapeutic approach in PTL remains a subject in reverse since it is a rare disease; to date we do not find any quality prospective study made on this subject. Actually, a multidisciplinary approach is proposed. The local control of the disease can be achieved by radiotherapy, surgery or both, however chemotherapy is reserved for cases where the dissemination is important which is the case for our patient [14].

Radiation therapy can achieve local control of the lymphoma, while chemotherapy can control distant dissemination of the disease. The conventional chemotherapeutic regimen for PTL includes cyclophosphamide, doxorubicin, vincristine and prednisone (CHOP). Typically, patients with PTL respond rapidly to this regimen. Systemic chemotherapy is usually associated with the typical radiation therapy (chemo-radiation therapy). Most of the time, radiation therapy is used after 3-6 courses of chemotherapy [10-12]. Combined chemo-radiation therapy is associated with a significantly lower risk of distant failure. Rituximab has recently been effectively used (with cyclophosphamide, mitoxantrone, vincristine, and prednisolone) in patients of advanced age with diffuse large B-cell lymphoma of thyroid [15].

\section{CONCLUSION}

Etiological diagnosis of DLBCL is mainly based on the performance of incisional biopsy; the treatment of choice should be combined chemoradiation instead of extensive surgery. Due to the rarity of the disease, each case must be evaluated and treated individually, since there is not a consensual therapeutic approach.

\section{REFERENCES}

1. Derringer, G. A., Thompson, L. D., Frommelt, R. A., Bijwaard, K. E., Heffess, C. S., \& Abbondanzo, S. L. (2000). Malignant lymphoma of the thyroid gland: a clinicopathologic study of 108 cases. The American journal of surgical pathology, 24(5), 623-639.

2. Sun, T. Q., Zhu, X. L., Wang, Z. Y., Wang, C. F., Zhou, X. Y., Ji, Q. H., \& Wu, Y. (2010). Characteristics and prognosis of primary thyroid non- Hodgkin's lymphoma in Chinese patients. Journal of Surgical Oncology, 101(7), 545-550.

3. Stein, S. A., \& Wartofsky, L. (2013). Primary thyroid lymphoma: a clinical review. The Journal of Clinical Endocrinology \& Metabolism, 98(8), 3131-3138.

4. Takashima, S., Takayama, F., Momose, M., Shingu, K., \& Sone, S. (2000). Secondary malignant lymphoma which simulated primary thyroid cancer. Clinical imaging, 24(3), 162-165.

5. Graff-Baker, A., Roman, S. A., Thomas, D. C., Udelsman, R., \& Sosa, J. A. (2009). Prognosis of primary thyroid lymphoma: demographic, clinical, and pathologic predictors of survival in 1,408 cases. Surgery, 146(6), 1105-1115.

6. Sun, T. Q., Zhu, X. L., Wang, Z. Y., Wang, C. F., Zhou, X. Y., Ji, Q. H., \& Wu, Y. (2010). Characteristics and prognosis of primary thyroid non- Hodgkin's lymphoma in Chinese patients. Journal of Surgical Oncology, 101(7), 545-550.

7. Holm, L. E., Blomgren, H., \& Löwhagen, T. (1985). Cancer risks in patients with chronic lymphocytic thyroiditis. New England Journal of Medicine, 312(10), 601-604.

8. Pedersen, R. K., \& Pedersen, N. T. (1996). Primary non- Hodgkin's lymphoma of the thyroid gland: a population based study. Histopathology, 28(1), 2532. Pedersen, R. K., \& Pedersen, N. T. (1996). Primary non- Hodgkin's lymphoma of the thyroid gland: a population based study. Histopathology, 28(1), 25-32.

9. Widder, S., \& Pasieka, J. L. (2004). Primary thyroid lymphomas. Current Treatment Options in Oncology, 5(4), 307-313.

10. KOSSEV, P., \& LIVOLSI, V. (1999). Lymphoid lesions of the thyroid: review in light of the revised European-American lymphoma classification and upcoming World Health Organization classification. Thyroid, 9(12), 1273-1280.

11. Cap, J., Ryska, A., Rehorkova, P., Hovorkova, E., Kerekes, Z., \& Pohnetalova, D. (1999). Sensitivity and specificity of the fine needle aspiration biopsy of the thyroid: clinical point of view. Clinical endocrinology, 51(4), 509.

12. Joshi, A., Chan, J., Bruch, G., Jeannon, J. P., Mikhaeel, N. G., Fields, P. A., \& Simo, R. (2009). Thyroid lymphoma and airway obstruction-is there a rationale for surgical management?. International journal of clinical practice, 63(11), 1647-1652.

13. MATSUZUKA, F., MIYAUCHI, A., KATAYAMA, S., NARABAYASHI, I., IKEDA, 
Ait Taleb Oum'hand Hajar et al., Saudi J Med Pharm Sci, Apr, 2021; 7(4): 191-194

H., KUMA, K., \& SUGAWARA, M. (1993).

Clinical aspects of primary thyroid lymphoma: diagnosis and treatment based on our experience of 119 cases. Thyroid, 3(2), 93-99.

14. Mack, L. A., \& Pasieka, J. L. (2007). An evidencebased approach to the treatment of thyroid lymphoma. World journal of surgery, 31(5), 978986. Mack, L. A., \& Pasieka, J. L. (2007). An evidence-based approach to the treatment of thyroid lymphoma. World journal of surgery, 31(5), 978-986.

15. Sakorafas, G. H., Kokkoris, P., \& Farley, D. R. (2010). Primary thyroid lympoma: Diagnostic and therapeutic dilemmas. Surgical oncology, 19(4), e124-e129. 